\title{
The Crisis of Biomedical Research Funding in Canada
}

Can. J. Neurol. Sci. 1997; 24: 271

As eloquently pointed out by Nobel laureate John Polanyi, it is sustainable generation of new knowledge by the scientific community in our universities supported by public funding that creates the "vocabulary" required for the "utterances" of innovative application by the commercial scientific community. The private sector is also fully aware of the causal link between the pipeline of new knowledge creation and commercial application, and that basic and applied science of the future will require well-trained individuals emerging from advanced training programs that are closely linked to basic research endeavour.

While this vision guides federal funding of universities and their research programs among competitor nations, Canadian provincial and federal governments, in their attempts to reduce the debts and deficits of their jurisdictions, have indiscriminately targeted university-based human resource and research programs that cut to the heart of its international competitiveness in knowledge generation, and the nation's future economic well-being. Compounding the problem in an attempt to legitimize the systematic reduction of public support, the federal government has further depleted the public purse focused on basic research, by shifting additional targeted funds to coerce private sector investment in support of the basic research that they have abandoned. Our governments have embarked on these programs without choosing to heed the message of Industry Canada and the private sector, that publicly funded support to build and sustain communities of inspired risk-taking scientists in our universities is essential for sustainable knowledge creation, innovation in application, and economic growth based on competitive advantage.

Contrast the "made in Canada" strategy with approaches being taken by some of our G-7 partners/competitors, all of whom face similar fiscal pressures. While their commitment to biomedical research has increased (percent cumulative change 1990-97; US - 48.9, UK - 38.6, Germany - 37.9), Canada has decreased its commitment during the same period $\left(-1.4^{1}\right)$. These countries, unlike Canada, have chosen not to sacrifice the intellectual capital of their universities, and the future economic well-being of their nations, on the altar of debt and deficit reduction programs. Perhaps the most troublesome aspect of the Canadian scenario is that it is not a phenomenon of the 1990s. Relative to our G-7 partners, Canadian governments have systematically avoided tangible commitment to the value of basic, curiosity-driven research in our universities, and in so doing have failed to recognize that there can be significant long-term economic returns on this investment. Witness the significant negative impact on our economic well-being from data demonstrating the very low adjusted ranking of Canada among our G-7 partners between the years 1980-1992 in bringing the fruits of knowledge-based discovery research to commercialization in the biomedical field. ${ }^{2}$

On a more positive note, this single example also provides evidence for the synergies that can emerge in knowledge creation and economic growth when all partners - universities, industry, and governments understand the unique roles they play in this tripartite partnership in the innovation chain. It will come as no surprise that those countries whose governments have made commitments to public support of basic research in universities are reaping the benefits of return investment from the quality of the knowledge generated, the strength of the partnerships with the private sector in the commercialization of this knowledge, and the provision of positions for scientists emerging from advanced university-based training programs. In other words where all players recognize their unique roles and contributions, public support of universities and the research programs has leveraged significant and far-reaching contributions from the private sector that are directly and indirectly benefitting the nation's intellectual capital in its universities and its economic well-being.

In the neurosciences, perhaps more than in any other biomedical discipline, the potential for revenue-side gains are matched by the potential for significant enhanced quality of life for individuals, and expense-side benefits for the nation. Reduction of direct and indirect costs of disease that emerge from generating new knowledge to create neurological and behavioural health, and from focusing innovation chain partnerships on treatment of chronic neurodegenerative (Alzheimer's disease, stroke, etc.) and neuropsychiatric (schizophrenia, depression, etc.) disorders will generate enormous savings for Canada's health care system.

The Canadian neurosciences research community is particularly well-placed to build on its international credibility, and on the infrastructure provided by its Neuroscience Network, and a dedicated neurosciences venture capital fund (Neuroscience Partners Fund), to participate in innovation chain partnerships with government and the private sector. The critical enabling requirement however, and so far the missing ingredient, is a tangible commitment by our governments to significant and sustainable investment in scientists and their research programs in our universities focused primarily on creating the "vocabulary" of new knowledge. Recently announced commitments by the federal government to build infrastructure for research in our universities, institutions, and hospitals must now be matched by a significant commitment to increase the pool of funds for competitive research support, and at the provincial level, by incremental funding for positions to enable recruitment to expand the scientist pool base.

Members of our society served by the professionals that constitute the membership of the Canadian Congress of Neurological Sciences stand to lose much if we, as their advocates, choose to remain supine and silent as the uninformed impulsiveness of party political machinery and governmental bureaucracies continue to erode the biomedical research base for the creation of health and treatment of illness. Indeed, the essence of our professionalism dictates a role for informed advocacy with our provincial and federal governments.

Richard John Riopelle Kingston, Ontario

\section{REFERENCES}

1. Coalition for Biomedical and Health Research, 1996.

2. D.F. Weaver, unpublished observations collated from Annual Reports in Medicinal Chemistry, 1982-1993. 